\title{
A prospective study of respiratory symptoms associated with chronic arsenic exposure in Bangladesh: findings from the Health Effects of Arsenic Longitudinal Study (HEALS)
}

\author{
Faruque Parvez, ${ }^{1}$ Yu Chen, ${ }^{2}$ Paul W Brandt-Rauf, ${ }^{1}$ Vesna Slavkovich, ${ }^{1}$ Tariqul Islam, ${ }^{3}$ \\ Alauddin Ahmed, ${ }^{3}$ Maria Argos, ${ }^{4}$ Rabiul Hassan, ${ }^{3}$ Mahbub Yunus, ${ }^{3}$ Syed E Haque, ${ }^{3}$ \\ Olgica Balac, ${ }^{1}$ Joseph H Graziano, ${ }^{1}$ Habibul Ahsan ${ }^{4}$
}

\begin{abstract}
${ }^{1}$ Department of Environmental Health Sciences, Mailman School of Public Health, Columbia University, New York, USA

${ }^{2}$ Department of Environmental Medicine, New York University School of Medicine, New York, USA

${ }^{3}$ Columbia University/University of Chicago Arsenic Research Office in Bangladesh, Dhaka, Bangladesh

${ }^{4}$ Department of Health Studies and Cancer Research Center, University of Chicago, Chicago, USA
\end{abstract}

\section{Correspondence to} Habibul Ahsan, Department of Health Studies and Comprehensive Cancer Center, University of Chicago, Chicago, USA; habib@uchicago.edu

Received 7 May 2009 Accepted 28 March 2010

\begin{abstract}
Background and aims A prospective cohort study was conducted to evaluate the effect of arsenic (As) exposure from drinking water on respiratory symptoms using data from the Health Effects of Arsenic Exposure Longitudinal Study (HEALS), a large prospective cohort study established in Ariahazar, Bangladesh in 2000-2002. A total of 7.31, 9.95 and $2.03 \%$ of the 11746 participants completing 4 years of active followup reported having a chronic cough, breathing problem or blood in their sputum, respectively, as assessed by trained physicians.
\end{abstract}

Methods Cox regression models were used to estimate HRs for respiratory symptoms during the follow-up period in relation to levels of chronic As exposure assessed at baseline, adjusting for age, gender, smoking, body mass index, education and arsenic-related skin lesion status. Results Significant positive associations were found between As exposure and respiratory symptoms. As compared with those with the lowest quintile of water As level $(\leq 7 \mu \mathrm{g} / \mathrm{l})$, the HRs for having respiratory symptoms were 1.27 (95\% Cl 1.09 to 1.48), 1.39 (95\% $\mathrm{Cl} 1.19$ to 1.63$), 1.43(95 \% \mathrm{Cl} 1.23$ to 1.68$)$ and 1.43 (95\% Cl 1.22 to 1.68$)$ for the second to fifth quintiles of baseline water As concentrations (7-40, 40-90, 90-178 and $>178 \mu \mathrm{g} / \mathrm{l})$, respectively. Similarly, the corresponding HRs in relation to the second to fifth quintiles of urinary arsenic were $1.10(95 \% \mathrm{Cl} 0.94$ to 1.27), 1.11 (95\% Cl 0.95 to 1.29$), 1.29$ (95\% Cl 1.11 to $1.49)$ and 1.35 (95\% Cl 1.16 to 1.56$)$, respectively. These associations did not differ appreciably by cigarette smoking status.

Conclusions This prospective cohort study found a dose-response relationship between As exposure and clinical symptoms of respiratory diseases in Bangladesh. In particular, these adverse respiratory effects of As were clearly evident in the low to moderate dose range, suggesting that a large proportion of the country's population may be at risk of developing serious lung diseases in the future.

\section{BACKGROUND}

Nearly 150 million people from Bangladesh and West Bengal continue to be exposed to arsenic (As) from drinking water despite the fact that As was identified as a carcinogen decades ago. ${ }^{1}$ It is well documented that As is related to an increased risk of lung, bladder and kidney cancers as well as adverse dermatological, reproductive and intellectual outcomes among adults and children. ${ }^{2-10}$

There is considerable evidence concerning nonmalignant respiratory effects of As although this is mostly based on studies with methodological limitations. ${ }^{11-17}$ Most of the published studies used retrospective designs, involved small sample sizes or measured As exposure ecologically. Evidence for the dose-response relationship between, in particular, low-level exposure and non-malignant respiratory diseases has not been well established.

To evaluate the effects of low to moderate levels of As exposure on the risk for respiratory symptoms, we conducted analyses using data from the Health Effects of Arsenic Longitudinal Study (HEALS) in Araihazar, Bangladesh, a prospective cohort established in 2000. Compared with most earlier studies, this study population has been exposed to a wide range of water As concentrations $(0.1-864 \mu \mathrm{g} / \mathrm{l})$ and includes a large number of study participants exposed to low to moderate levels of As, thus providing a unique opportunity to examine relationships between As exposure and the risk of symptoms of respiratory disease at low to moderate levels of exposure.

\section{METHODS}

\section{Study participants}

Using population-based sampling, the HEALS cohort recruited 11746 participants during 2000-2002 in Araihazar, Bangladesh. The overall goal of the HEALS study is to examine health effects of As exposure from drinking water and mitigation strategies in order to guide relevant prevention strategies and policies. A detailed description of the study has been published elsewhere. $^{18} 19$ In brief, between October 2000 and May 2002, 11746 adults who consumed groundwater with a wide range of As concentrations for at least 3 years were recruited. Since recruitment, the cohort has been actively followed-up by trained study physicians every 2 years with in-person home visits. Demographic and lifestyle data, water and urine samples were collected at baseline and at each follow-up visit. Assessment of respiratory symptoms (see below) was also conducted during the visit. This study was approved by the Institutional Review Boards of Columbia University, University 
of Chicago and the Bangladesh Medical Research Council. The current study included the original 11746 cohort members who underwent the first two follow-up visits that took place in September 2002-May 2004 and April 2004-August 2006.

\section{Assessment of respiratory symptoms}

At baseline, information on respiratory symptoms was collected through the following question: 'Do you have any problems in breathing with normal daily activities or due to any illness?' All participants answering 'yes' to this question at baseline were excluded from the current analyses. During the follow-up visits, trained study physicians, who were blind to As exposure history and baseline disease status, assessed each participant for respiratory illness (and other illnesses) using a structured clinical protocol. Respiratory symptoms identified at follow-up were based on the following three separate questions: (1) 'Do you have a frequent cough that has lasted for over 3 months in the past year?'; (2) 'Do you have difficulty in breathing?'; and (3) 'Do you have a cough that is accompanied by blood?'. The presence of respiratory symptoms was defined as having answered 'yes' to any of these questions.

\section{Sample collection, storage and processing: Water sample collection and As assay}

Water samples from the wells from which the study participants drank regularly were collected in $50 \mathrm{ml}$ acid-washed tubes following pumping of the well for $5 \mathrm{~min}$. These samples were analysed for As concentration by graphite furnace atomicabsorption (GFAA) with a Hitachi Z-8200 system in the Geochemistry Laboratory at Lamont Doherty Earth Observatory of Columbia University. A detailed description of the water collection procedure is presented elsewhere. ${ }^{20}$ Those water samples that had an As concentration less than the detection limit $(5 \mu \mathrm{g} / \mathrm{l})$ were subsequently analysed by an Axiom Single Collection high-resolution inductively coupled mass spectrometer (ICP-MS) which has a detection limit of $0.1 \mu \mathrm{g} / \mathrm{l}$. Analyses for time-series samples collected from 20 tube wells in the study area showed that the As concentration in well water is relatively stable over time. ${ }^{21}$

\section{Urine sample collection and As assay}

At each visit, spot urine samples were collected in $50 \mathrm{ml}$ acidwashed tubes and kept in portable coolers with ice-packs (carried by the research team) until storage in $-20^{\circ} \mathrm{C}$ freezers within 3-5h. All samples were frozen until shipment to Columbia University on dry ice. Urinary As analyses were performed with GFAA using a Perkin-Elmer Analyst 600 graphite furnace system in the trace metal core laboratory at Columbia University, as described. ${ }^{22}$ Levels of As in urine were expressed as micrograms of As per gram of creatinine. Creatinine was analysed by a colorimetric method based on the Jaffe reaction and it was used to correct for differences in urine concentration. In a random sample of $10 \%$ of the cohort $(n=1123)$, urine samples were further analysed to distinguish individual urinary As metabolites. ${ }^{23}$ The correlation of arsenobetaine and arsenocholine with total urinary As was weak $(<0.10) .{ }^{23}$ On the other hand, the correlation between total urinary As and As from the wells was $0.76 .^{8} 24$ Therefore, analyses were not adjusted for seafood consumption.

\section{Statistical analysis}

We considered the primary outcome as a positive response to any of the three respiratory symptom questions at any of the two follow-up visits in cohort analyses. Participants with breathing problems with normal daily activities or due to any illness were excluded. The analysis included a total of 10833 participants with absence of problems with breathing and coughing at baseline.

Cox proportional hazard models were used to estimate the HRs for respiratory symptoms detected at follow-up visits in relation to age, gender, demographic and lifestyle variables, and levels of baseline well As and urinary As concentrations. We computed HRs in relation to various As exposure levels adjusting for potential confounding variables including age, gender, educational attainment, smoking status, body mass index (BMI), visit to visit changes in urinary As and well switching status. The status of respiratory symptoms at the follow-up visits was considered censored for those who died ( $n=201)$, moved $(n=463)$ or who were lost to follow-up $(n=152)$. We calculated person-years of observation from the date of the baseline visit to the date of the follow-up visit for those who reported having respiratory symptoms, to the date of death for those who had died, to the date of the move reported by close relatives or neighbours for those who moved and to the date of the last follow-up visit for those who reported not having any respiratory symptoms. Urine samples were provided by $95.6,94.5$ and $91.2 \%$ of the total cohort participants at baseline, first follow-up and second follow-up, respectively. Individuals with missing data on visit to visit changes in urinary As were included in the analyses using an indicator variable. Analyses were also conducted excluding these participants; the results were similar and therefore are not shown.

In addition, to evaluate whether there was an interaction between As exposure and cigarette smoking, we computed HRs in relation to joint As exposure and smoking status. All analyses were conducted using the SAS 9.1.3 statistical package for Windows (SAS Institute, Cary, North Carolina, USA).

\section{RESULTS}

In total, 1874 (15.95\%) participants had experienced at least one respiratory symptom; 7.31, 9.95 and $2.03 \%$ of participants reported having chronic cough, breathing problems or blood in their sputum, respectively. The average age of the study participants was 39 years at baseline.

Table 1 shows the HRs for the effect of As exposure at baseline and respiratory symptoms during follow-up adjusted for demographic and lifestyle factors including age, gender, duration of education, smoking, presence of skin lesions and well switching status. Older participants were more likely to have respiratory symptoms. Participants aged $30-40$ years and older ( $>40$ years) showed significantly higher rates of respiratory symptoms (HR 1.16, 95\% CI 1.02 to 1.32 ; and $\operatorname{HR} 1.51,95 \%$ CI 1.32 to 1.72 , respectively) than those under 30 years. Overall the rate of respiratory symptoms was greater among smokers (HR 1.93, 95\% CI 1.67 to 2.22 ) as compared with never smokers. The HRs for having a respiratory symptom(s) were $1.56(95 \%$ CI 1.27 to 1.92), 2.03 (95\% CI 1.73 to 2.37 ) and 2.15 (95\% CI 1.80 to 2.58) for past smokers, current light smokers and current heavy smokers, respectively, as compared with never smokers, suggesting a dose-response effect of smoking. After adjustment for smoking and other variables, women had a higher risk of respiratory effects than men (HR 1.35, $95 \%$ CI 1.17 to 1.56$)$. Individuals with a lower BMI ( $\leq 18)$ had a slightly higher risk of experiencing a respiratory problem (HR 1.11, 95\% CI 1.02 to 1.32). Interestingly, we also observed a strong inverse association between duration 
Table 1 HRs* for respiratory symptoms in relation to baseline demographic, lifestyle, and arsenic exposure variables†

\begin{tabular}{|c|c|c|c|}
\hline Baseline variables & $\begin{array}{l}\text { Total no. (with and } \\
\text { without respiratory } \\
\text { symptoms) } n=10833\end{array}$ & $\begin{array}{l}\text { No. with respiratory } \\
\text { symptoms } n=1874\end{array}$ & HR $(95 \%$ Cl $) \neq$ \\
\hline \multicolumn{4}{|l|}{ Age (in years) } \\
\hline$\leq 30$ & 3614 & 426 & 1.00 \\
\hline $30-40$ & 3777 & 633 & 1.16 (1.02 to 1.32$)$ \\
\hline$>40$ & 3430 & 814 & 1.51 (1.32 to 1.72$)$ \\
\hline \multicolumn{4}{|l|}{ Gender } \\
\hline Male & 4648 & 977 & 1.00 \\
\hline Female & 6185 & 897 & 1.35 (1.17 to 1.56$)$ \\
\hline \multicolumn{4}{|l|}{ Body mass index } \\
\hline$\leq 18$ & 3709 & 612 & 1.11 (0.99 to 1.24$)$ \\
\hline $18-20.5$ & 3291 & 672 & 1.00 \\
\hline$>20.5$ & 3562 & 548 & 1.07 (0.95 to 1.21$)$ \\
\hline Unknown & 271 & 42 & \\
\hline \multicolumn{4}{|c|}{ Educational attainment (in years) } \\
\hline No formal & 4754 & 977 & 1.00 \\
\hline $1-6$ & 3556 & 565 & $0.79(0.71$ to 0.88$)$ \\
\hline$\geq 6$ years & 2517 & 331 & $0.67(0.59$ to 0.77$)$ \\
\hline \multicolumn{4}{|c|}{ Baseline water arsenic concentration $(\mu \mathrm{g} / \mathrm{l})$} \\
\hline$\leq 7$ & 2300 & 333 & 1.0 \\
\hline $7-40$ & 2175 & 373 & 1.27 (1.09 to 1.48$)$ \\
\hline $40-90$ & 2034 & 372 & $1.39(1.19$ to 1.63$)$ \\
\hline $90-178$ & 2170 & 393 & $1.43(1.23$ to 1.68$)$ \\
\hline$>178$ & 2154 & 403 & $1.43(1.22$ to 1.68$)$ \\
\hline \multicolumn{4}{|c|}{ Baseline urinary arsenic concentration ( $\mu \mathrm{g} / \mathrm{g}$ creatinine) } \\
\hline$\leq 90$ & 2110 & 306 & 1.0 \\
\hline $90-160$ & 2102 & 345 & $1.10(0.94$ to 1.27$)$ \\
\hline $160-246$ & 2037 & 342 & $1.11(0.95$ to 1.29$)$ \\
\hline $246-406$ & 2034 & 378 & 1.29 (1.11 to 1.49$)$ \\
\hline$>406$ & 2039 & 420 & 1.35 (1.16 to 1.56$)$ \\
\hline Unknown & 511 & 83 & \\
\hline \multicolumn{4}{|l|}{ Smoking status } \\
\hline Never & 7048 & 927 & 1.0 \\
\hline Past smoker & 679 & 144 & 1.56 (1.27 to 1.92$)$ \\
\hline Current light smoker§ & 1841 & 462 & 2.03 (1.73 to 2.37$)$ \\
\hline Current heavy smoker & 1257 & 339 & 2.15 (1.80 to 2.58$)$ \\
\hline \multicolumn{4}{|l|}{ Prevalent skin lesions } \\
\hline No & 9933 & 1654 & 1.0 \\
\hline Yes & 691 & 182 & 1.09 (0.92 to 1.28$)$ \\
\hline Unknown & 209 & 38 & \\
\hline \multicolumn{4}{|l|}{ Well switching status } \\
\hline No & 6201 & 1121 & 1.0 \\
\hline Yes & 4099 & 726 & 0.90 (0.81 to 0.99$)$ \\
\hline Unknown & 533 & 27 & \\
\hline
\end{tabular}

*Estimated from Cox proportional hazard models.

†Cut-off points were determined on the quintiles of the overall study population.

$¥$ HRs for each of the variables were adjusted for all the other variables in the table except that HRs for well arsenic were not adjusted for urinary arsenic, and vice versa.

$\S$ Light and heavy smokers were defined using the median value of daily cigarette consumption among current smokers.

of education and the risk of respiratory symptoms: the HR for respiratory symptoms was markedly decreased for those with 1-6years and $>6$ years of school attendance compared with those with no formal education. The risk of respiratory symptoms did not differ by skin lesion status at baseline. About $40 \%$ of the study participants reported that they had switched to drinking water from low As-contaminated wells since baseline. Individuals who had switched were less likely to report having any respiratory symptoms compared with those who did not switch.

There was a dose-response relationship between baseline As exposure levels, measured using either water As or urinary As, and risk of respiratory symptoms. For instance, the HRs of respiratory symptoms were 1.00 (reference), 1.27 (95\% CI 1.09 to 1.48), 1.39 (95\% CI 1.19 to 1.63 ), 1.43 (95\% CI 1.23 to 1.68 ) and 1.43 (95\% CI 1.22 to 1.68$)$ for increasing quintiles of water As concentration $(\leq 7,7-40,40-90,90-178$ and $>178 \mu \mathrm{g} / \mathrm{l})$. The HRs for respiratory symptoms were 1.00 (reference) 1.10 (95\% CI 0.94 to 1.27 ), 1.11 (95\% CI 0.95 to 1.29$), 1.29$ (95\% CI 1.11 to 1.49 ) and 1.35 (95\% CI 1.16 to 1.56 ) for increasing quintiles of baseline urinary As concentration ( $\leq 90,90-160,160-246,246-406$ and $>406 \mu \mathrm{g} /$ $\mathrm{g}$ creatinine), after adjustment for visit to visit urinary As changes and other variables. The HRs among participants without skin lesions remained similar to those without lesions, and 
a dose-response effect was still seen. Among participants without skin lesions at baseline, the HRs associated with well As were 1.00 (reference), 1.24 (95\% CI 1.06 to 1.44 ), 1.35 (95\% CI 1.15 to 1.59 ), $1.38(95 \%$ CI 1.17 to 1.62$)$ and 1.40 (95\% CI 1.18 to 1.65$)$ with increasing quintiles of well As.

The relationships between As exposure variables and each of the three recorded respiratory problems are summarised in table 2. In general, the associations between well As and individual symptoms were stronger than those between urinary As and symptoms. The HRs for having both chronic cough and breathing problems were 1.00 (reference), 1.56 (95\% CI 1.02 to 2.39), 1.81 (95\% CI 1.18 to 2.79 ), 1.93 (95\% CI 1.25 to 2.98 ) and 1.82 (95\% CI 1.16 to 2.84$)$ in relation to increasing quintiles of well As, and were 1.00 (reference), 1.15 (95\% CI 0.74 to 1.76), 1.36 (95\% CI 0.90 to $2.07), 1.75$ (95\% CI 1.16 to 2.62$)$ and 1.61 (95\% CI 1.06 to 2.44$)$ in relation to increasing quintiles of urinary As.

Examination of the risk of respiratory symptoms in relation to joint status of smoking and As exposure suggests an additive effect of the two factors, such that at any given level of As exposure, the risk of having respiratory symptoms was greater among ever smokers compared with never smokers (table 3). The patterns of HRs associated with water and urinary As exposure were consistent. Compared with never smokers with the lowest level of water As, the risk associated with the highest level of As exposure alone ( $\mathrm{HR}=1.37)$ was comparable with the risk associated with smoking alone $(\mathrm{HR}=1.50)$ (table 3$)$.

\section{DISCUSSION}

To our knowledge, this is the first large prospective cohort study that systematically evaluated As-induced respiratory effects with detailed data on low to moderate levels of As exposure measured at the individual level. We found a strong dose-response relationship between both baseline water and urinary As concentrations and clinical symptoms of respiratory disease. More importantly, the findings suggest adverse effects on respiratory symptoms at lower concentrations of water As than reported earlier by others. ${ }^{11-14}$ We also found that the effects of smoking and As on respiratory symptoms were no more than additive (no synergistic interaction).

Some studies from South America and Asia have also reported that high levels of As exposure are associated with non-malignant respiratory effects in populations living in Asendemic areas. ${ }^{11-17}$ For instance, reports from As-endemic areas in Chile showed a high mortality and incidence of chronic obstructive pulmonary disease (COPD) and bronchiectasis among adults and children. ${ }^{7} 16$ Studies conducted in India and Bangladesh have found an increased risk of respiratory illnesses and a reduced level of lung function among individuals with high levels of As in their water $(>500 \mu \mathrm{g} / \mathrm{l})$ or arsenical skin lesions. ${ }^{11-15}$ A study from Inner Mongolia reported a 13-fold increased risk for cough and a high prevalence of bronchitis among people living in As-exposed villages. ${ }^{17}$ However, these studies used retrospective designs, included small sample sizes or measured As exposure ecologically. In addition, compared with these studies, we observed respiratory effects at a much lower level of As exposure. These findings warrant future studies of the effects of low-level As exposure on clinically diagnosed respiratory disease.

Previous studies have shown a positive association between As exposure and respiratory symptoms primarily among individuals with skin lesions and exposed to high levels of As in drinking water. $^{12}{ }^{13}$ For instance, four studies from India and Bangladesh found individuals with skin lesions or drinking water contaminated with high As concentrations $(>500 \mu \mathrm{g} / \mathrm{l})$ had a risk of cough and breathing problems ${ }^{11-14} 25$ of between two and 15 times greater than individuals without skin lesions. An earlier study in Chile reported excessive cough (38\%) among school children with skin lesions and living in an As-endemic area. ${ }^{16} \mathrm{~A}$ higher prevalence of respiratory symptoms among people with skin lesions could also be partly due to recall bias. ${ }^{1125} 26$ This could also explain why previous cross-sectional and case-control studies reported a much stronger association between skin lesion status and respiratory symptoms than our study. ${ }^{11} 12$ Although we could not eliminate the potential recall bias in our study due to the fact that the assessment of respiratory symptoms was based on self-reported data, in our analyses the association between As exposure and respiratory symptoms was also clearly evident in participants with no skin lesions-a finding that cannot be explained by the potential recall bias. In addition, skin lesion status was not associated with risk of respiratory symptoms after controlling for As exposure in the analyses.

One previous study has observed As exposure-induced breathing problems (OR 2.8, 95\% CI 1.1 to 7.6) and cough (OR $2.8,95 \%$ CI 1.2 to 6.6 ) and a $60 \%$ decreased lung function among smokers. ${ }^{15}$ Our analyses reveal that smoking increases respiratory symptoms significantly among past and present smokers as compared with never smokers (table 1). However, cigarette smoking did not significantly modify the relationship between As exposure and respiratory symptoms. Nevertheless, it is

Table 2 HRs $^{*}$ for respiratory symptoms by levels of baseline water and urinary arsenic concentrations $\dagger$

\begin{tabular}{|c|c|c|c|}
\hline & $\begin{array}{l}\text { Chronic cough HR } \\
(95 \% \mathrm{CI}) \mathrm{n}=859\end{array}$ & $\begin{array}{l}\text { Breathing problem HR } \\
(95 \% \mathrm{Cl}) \mathrm{n}=\mathbf{1 1 6 9}\end{array}$ & $\begin{array}{l}\text { Blood in sputum HR } \\
(95 \% \mathrm{Cl}) \mathrm{n}=\mathbf{2 3 8}\end{array}$ \\
\hline \multicolumn{4}{|c|}{ Water arsenic $(\mu \mathrm{g} / \mathrm{l})$} \\
\hline$\leq 7$ & 1.0 & 1.0 & 1.0 \\
\hline $7-40$ & $1.19(0.95$ to 1.50$)$ & $1.44(1.20$ to 1.74$)$ & $1.15(0.75$ to 1.76$)$ \\
\hline $40-90$ & $1.40(1.11$ to 1.75$)$ & $1.52(1.25$ to 1.84$)$ & 1.09 (1.69 to 1.70$)$ \\
\hline $90-178$ & 1.57 (1.25 to 1.97$)$ & $1.42(1.16$ to 1.73$)$ & 1.66 (1.10 to 2.51$)$ \\
\hline$>178$ & 1.60 (1.27 to 2.01$)$ & 1.41 (1.56 to 1.72$)$ & 1.51 (0.98 to 2.32$)$ \\
\hline \multicolumn{4}{|c|}{ Urinary arsenic ( $\mu \mathrm{g} / \mathrm{g}$ creatinine) } \\
\hline$\leq 90$ & 1.0 & 1.0 & 1.0 \\
\hline $90-160$ & $0.98(0.78$ to 1.23$)$ & 1.14 (0.95 to 1.38$)$ & $1.16(0.77$ to 1.74$)$ \\
\hline $160-246$ & $1.14(0.91$ to 1.42$)$ & $1.16(0.96$ to 1.40$)$ & $1.05(0.69$ to 1.60$)$ \\
\hline $246-406$ & $1.52(1.23$ to 1.88$)$ & 1.28 (1.06 to 1.54$)$ & $1.03(0.67$ to 1.58$)$ \\
\hline$>406$ & $1.51(1.21$ to 1.87$)$ & $1.27(1.05$ to 1.53$)$ & $1.33(0.89$ to 1.99$)$ \\
\hline
\end{tabular}

Adjusted for age, gender, body mass index, smoking, education, skin lesion and well switching status.

*Estimated from Cox proportional hazard models.

†Cut-off points were determined on the quintiles of the overall study population. 
Table $3 \mathrm{HRs}^{*}$ for respiratory symptoms in relation to joint baseline smoking status and baseline arsenic exposure levels $\dagger$

\begin{tabular}{|c|c|c|c|c|}
\hline & Effect modifier & $\begin{array}{l}\text { Numbers (cases/total within } \\
\text { exposure level) }\end{array}$ & $\begin{array}{l}\text { HR for respiratory symptoms } \\
\text { (stratified analyses) }\end{array}$ & $\begin{array}{l}\text { HR for respiratory symptoms } \\
\text { (joint effect) }\end{array}$ \\
\hline Water arsenic $(\mu \mathrm{g} / \mathrm{l})$ & Smoking status & $\mathrm{n}=927 / 7048$ & & \\
\hline$\leq 7$ & Never & $177 / 1498$ & 1.0 (ref) & 1.0 (ref) \\
\hline $40-90$ & Never & $169 / 1311$ & $1.11(0.89-1.38)$ & $1.11(0.89-1.38)$ \\
\hline $90-178$ & Never & $183 / 1413$ & $1.15(0.92-1.43)$ & $1.14(0.92-1.42)$ \\
\hline$>178$ & Never & $\begin{array}{l}215 / 1400 \\
n=946 / 3780\end{array}$ & $1.39(1.12-1.73)$ & $1.37(1.11-1.69)$ \\
\hline $7-40$ & Ever & $190 / 749$ & $1.43(1.14-1.78)$ & $2.18(1.72-2.76)$ \\
\hline $40-90$ & Ever & $202 / 722$ & $1.72(1.38-2.14)$ & $2.63(2.08-3.32)$ \\
\hline $90-178$ & Ever & $210 / 757$ & $1.75(1.40-2.18)$ & $2.70(2.14-3.42)$ \\
\hline$>178$ & Ever & $188 / 752$ & $1.45(1.15-1.83)$ & $2.25(1.77-2.87)$ \\
\hline Urinary arsenic ( $\mu \mathrm{g} / \mathrm{g}$ creatinine) & Smoking status & $\mathrm{n}=882 / 6692$ & & \\
\hline$\leq 90$ & Never & $154 / 1328$ & 1.0 (ref) & 1.0 (ref) \\
\hline & & $\mathrm{n}=908 / 3625$ & & \\
\hline$\leq 90$ & Ever & $152 / 781$ & 1.0 & $1.63(1.27-2.10)$ \\
\hline $90-160$ & Ever & $165 / 728$ & $1.10(0.88-1.36)$ & $1.86(1.45-2.38)$ \\
\hline $160-246$ & Ever & $195 / 784$ & $1.25(1.01-1.54)$ & $2.15(1.69-2.74)$ \\
\hline $246-406$ & Ever & $197 / 693$ & $1.47(1.19-1.82)$ & $2.56(2.01-3.26)$ \\
\hline$>406$ & Ever & $199 / 639$ & $1.47(1.18-1.82)$ & $2.53(1.99-3.22)$ \\
\hline
\end{tabular}

Adjusted for age, gender, body mass index, smoking, education, skin lesion and well switching status.

*Estimated from Cox proportional hazard models.

tCut-off points were determined on the quintiles of water and urinary arsenic.

interesting to note that the risk associated with the highest level of As exposure alone is comparable with the risk associated with smoking alone (table 3), indicating that As exposure may be as strong a risk factor for respiratory illness as smoking in Bangladesh. Given that the effect is evident even at a low dose range, and that As exposure is equally prevalent in men and in women (unlike smoking), the future burden of respiratory illness due to As exposure in Bangladesh could be substantial.

The role of gender on respiratory effects remains somewhat unclear. ${ }^{9}$ For instance, two studies from India reported a higher risk for respiratory symptoms in males, while one from Bangladesh found a higher risk in females. ${ }^{11-13}$ Interestingly, one study reported a higher risk for respiratory symptoms among males, but observed statistically significant effects only among females exposed to high levels of As. ${ }^{11}$ We found that there was a higher risk in females compared with males (HR 1.35, 95\% CI 1.17 to 1.56) after adjusting for smoking status. The dose-response relationship between As exposure levels and respiratory symptoms however does not differ appreciably by gender (data not shown). Other factors such as nutritional factors and indoor air pollution from cooking might explain some of the differences in risks across gender ${ }^{1125} 28$; however, more research is needed to uncover the underlying mechanisms.

In our analyses, we controlled for changes in urinary As over time since baseline, and we found that the baseline As exposure levels were predictive of respiratory symptoms. Changes in As exposure, measured using visit to visit urinary As, however, were not related to the risk of respiratory symptoms (data not shown). We estimated that the pair-wise correlation between urinary As measured at each visit was high (all $\geq 0.60$ ). On average, in the overall cohort, the urinary As level decreased by $52 \mu \mathrm{g} / \mathrm{g}$ creatinine from baseline to the first follow-up visit and then stayed at the same level at the second follow-up, with a high correlation (0.74) between urinary As at the two follow-up visits. A study among 398 school children in Antofagasta, Chile has reported a reduction of cough from 38\% to $7 \%$ after an As removal plant was installed in the area. ${ }^{16}$ However, the sample size of the study was small and the reliability of selfreported symptoms in children is questionable. With longer follow-up times in our cohort, future analyses will include the evaluation of the effects of long-term changes in As exposure on the risk of respiratory diseases.

A limitation of this study is that information on respiratory symptoms was collected at baseline and follow-up using questions which were not exactly the same. Therefore, although we conducted prospective analyses, some of the study participants with chronic cough but no breathing problems at baseline may have been included in the analyses, and thus our effect estimates may not reflect true incidence cases. However, the association between As exposure and having both breathing problems and chronic cough remained strong and significant, providing evidence of the adverse effect of As exposure on subsequent risk of multiple respiratory symptoms. Although the reliability and validity of the questions for respiratory symptoms were not assessed before the study, the relationships between conventional risk factors for respiratory diseases and respiratory symptoms were consistent with the literature, suggesting content validity of the outcomes. In a subsample of 112 subjects with lung function test results available, lung function level decreased with increasing number of symptoms (data not shown), suggesting the validity of the questions. Further studies are needed to evaluate the relationship between As exposure and respiratory end points based on more extensive diagnostic tests.

The mechanism of As-induced non-malignant respiratory effects is not known. However, tissue inflammation by deposition of As on the epithelium and damage has been suggested. ${ }^{26}$ This may increase pulmonary fibrosis and ultimately impair lung function. ${ }^{29-32}$ De and colleagues suggest that As may induce lung 
toxicity by inflammation mediated through the immune response. ${ }^{13}$ One study in 125 individuals with arsenical lesions in Bangladesh observed a reduced level of immune response induced by As, suggesting that As induces toxicity by changing the humoral and mucosal responses. ${ }^{33}$ Previous findings from our group on the association between As and the serum level of Clara cell protein CC16 also provided a biological basis for the adverse effects of As exposure on respiratory function. ${ }^{26}$

In summary, compared with previous reports, we observed respiratory effects at a much lower level of As exposure in this Bangladeshi population. This finding indicates that $~ 80 \%$ of the HEALS participants and their families and a vast majority of the country's population are at an increased risk of developing serious respiratory diseases (including COPD, bronchitis and interstitial lung disease) in future. ${ }^{12} 1334$ Future As mitigation and research activities should focus not only on high As-endemic areas but also on areas with relatively low exposures to evaluate the mortality and morbidity due to As-related respiratory diseases.

Acknowledgements We would like to thank our staff, field workers and study participants in Bangladesh without whom this work would have been impossible.

Funding This research was supported by US National Institutes of Health Grants P42 ES10349, P30 ES09089, R01 CA107431 and R01 CA102484.

Competing interests None.

Ethics approval This study was conducted with the approval of the Institutional Review Boards of Columbia University, University of Chicago and the Bangladesh Medical Research Council.

Provenance and peer review Not commissioned; externally peer reviewed.

\section{REFERENCES}

1. Rahman MM, Chowdhury UK, Mukherjee SC, et al. Chronic arsenic toxicity in Bangladesh and West Bengal, India-a review and commentary. J Toxicol Clin Toxicol 2001;39:683-700.

2. Chiou HY, Hsueh YM, Liaw KF, et al. Incidence of internal cancers and ingested inorganic arsenic: a seven-year follow-up study in Taiwan. Cancer Res 1995;55:1296-300.

3. Smith AH, Goycolea M, Haque R, et al. Marked increase in bladder and lung cancer mortality in a region of Northern Chile due to arsenic in drinking water. Am J Epidemiol 1998;147:660-9.

4. Celik I, Gallicchio L, Boyd K, et al. Arsenic in drinking water and lung cancer: a systematic review. 2008. Environ Res 2008:108:48-55.

5. Marshall G, Ferreccio C, Yuan Y, et al. Fifty-year study of lung and bladder cancer mortality in Chile related to arsenic in drinking water. J Nat/ Cancer Inst 2007:99:920-8.

6. Steinmaus C. Bates MN, Yuan Y et al. Arsenic methylation and bladder cancer risk in case-control studies in Argentina and the United States. J Occup Environ Med 2006;48:478-88.

7. Hopenhayn-Rich C, Biggs ML, Smith AH. Lung and kidney cancer mortality associated with arsenic in drinking water in Córdoba, Argentina. Int $\mathrm{J}$ Epidemiol 1998:27:561-9

8. Ahsan H, Chen Y, Parvez F, et al. Arsenic exposure from drinking water and risk of premalignant skin lesions in Bangladesh: baseline results from the Health Effects of Arsenic Longitudinal Study (HEALS). Am J Epidemiol 2006:163:1138-48.

9. Milton AH, Smith W, Rahman B, et al. Chronic arsenic exposure and adverse pregnancy outcomes in Bangladesh. Epidemiology 2005;16:82-6.

10. Wasserman GA, Liu X, Parvez F, et al. Water arsenic exposure and intellectual function in 6-year-old children in Araihazar, Bangladesh. Environ Health Perspect 2007:115:285-9.
11. Mazumder DN, Haque R, Ghosh N, et al. Arsenic in drinking water and the prevalence of respiratory effects in West Bengal, India. Int J Epidemiology 2000;29:1047-52.

12. Mazumder DN, Steinmus C, Bhattacharaya $P$, et al. Bronchitis in persons with skin lesions resulting from arsenic in drinking water. Epidemiology 2005;16:760-5.

13. De BK, Majumdar D, Sen $S$, et al. Pulmonary involvement in chronic arsenic poisoning from drinking contaminated ground-water. J Assoc Physicians India 2004;52:395-400.

14. Milton AH, Rahman M. Respiratory effects and arsenic contaminated well water in Bangladesh. Int J Environ Health Res 2002;12:175-9.

15. von Ehrenstein OS, Mazumder DN, Yuan $Y$, et al. Decrements in lung function related to arsenic in drinking water in West Bengal, India. Am J Epidemiol 2005; 162:533-41.

16. Zaldivar R, Ghai GL. Clinical epidemiological studies on endemic chronic arsenic poisoning in children and adults, including observations on children with high- and low-intake of dietary arsenic. Zentralb/ Bakteriol [B] 1980;170:409-21.

17. Guo JX, Hu L, Yand PZ, et al. Chronic arsenic poisoning in drinking water in Inner Mongolia and its associated health effects. J Environ Sci Health A Tox Hazard Subst Environ Eng 2007:42:1853-8.

18. Ahsan H, Chen $Y$, Parvez $F$, et al. Health effects of arsenic longitudinal study (HEALS): description of a multidisciplinary epidemiologic investigation. J Expo Sci Environ Epidemiol 2006;16:191-205.

19. Parvez F, Chen $Y$, Argos $M$, et al. Prevalence of arsenic exposure from drinking water and awareness of its health risks in a Bangladeshi population: results from a large population-based study. Environ. Health Perspect 2006:114:355-9.

20. Van Geen A, Ahsan H, Horneman AH, et al. Promotion of well-switching to mitigate the current arsenic crisis in Bangladesh. Bull WHO 2002;80:732-7.

21. Cheng Z, van Geen A, Seddique AA, et al. Limited temporal variability of arsenic concentrations in 20 wells monitored for 3 years in Araihazar, Bangladesh. Environ Sci Technol 2005:39:4759-66.

22. Nixon DE, Mussmann GV, Eckdahl SJ, et al. Total arsenic in urine: palladiumpersulfate vs nickel as a matrix modifier for graphite furnace atomic absorption spectrophotometry. Clin Chem 1991:37:1575-9.

23. Ahsan H, Chen Y, Kibriya MG, et al. Arsenic metabolism, genetic susceptibility, and risk of premalignant skin lesions in Bangladesh. Cancer Epidemiol Biomarkers Prev 2007:16:1270-8.

24. Hall M, Chen $\mathrm{Y}$, Ahsan $\mathrm{H}$, et al. Blood arsenic as a biomarker of arsenic exposure Toxicology 2006;225:225-33.

25. Milton AH, Hasan Z, Atiqur Rahman A, et al. Chronic arsenic poisoning and respiratory effects in Bangladesh. J Occup Health 2001;43:136-40.

26. Parvez F, Chen Y, Brandt-Rauf PW, et al. Nonmalignant respiratory effects of chronic arsenic exposure from drinking water among never-smokers in Bangladesh. Environ Health Perspect 2008:116:190-5.

27. McCarty KM, Ryan L, Houseman EA, et al. A case-control study of GST polymorphisms and arsenic related skin lesions. Environ Health 2007:6:5.

28. Gamble MV, Liu X, Ahsan $\mathrm{H}$, et al. Folate, homocysteine, and arsenic metabolism in arsenic-exposed individuals in Bangladesh. Environ Health Perspect 2005;113:1683-8.

29. Gerhardsson L, Brune D, Nordberg GF, et al. Multielemental assay of tissues of deceased smelter workers and controls. Sci Total Environ 1988;74:97-110.

30. Hotta N. Clinical aspects of chronic arsenic exposure poisoning due to environmental and occupational pollution in and around a small refining spot. Jpn J Constitutional Med 1989;53:49-70.

31. Rosenberg HG. Systemic arterial disease and chronic arsenicism in infants Arch Pathol 1974:97:360-5.

32. Saady JJ, Blanke RV, Poklis A. Estimation of the body burden of arsenic in a child fatally poisoned by arsenite weedkiller. J Anal Toxicol 1989:13:310-12.

33. Islam LN, Nabi AH, Rahman MM, et al. Association of respiratory complications and elevated serum immunoglobulins with drinking water arsenic toxicity in human. J Environ Sci Health A Tox Hazard Subst Environ Eng 2007:42: 1807-14.

34. Smith AH, Marshall G, Yuan Y, et al. Increased mortality from lung cancer and bronchiectasis in young adults after exposure to arsenic in utero and in early childhood. Environ Health Perspect 2006;114:1293-6. 